\title{
Aortic annular measurements in fresh post-mortem hearts: a study in Sri Lankans
}

\section{S Udhayakumar ${ }^{1}$, S G Yasawardene ${ }^{2}$}

(Index words: basal aortic annular diameter, basal aortic root circumference, demographic data, fresh post mortem)

\begin{abstract}
The basal aortic root measurements were determined in 320 fresh, autopsied, normal, adult, Sri Lankan hearts collected from the Judicial Medical Office, National Hospital of Sri Lanka. The correlation between the measurements and demographic data of the individual was calculated. The mean aortic root circumference at the basal ring was $64.7 \mathrm{~mm} \pm 7 \mathrm{SD}$ (males $66.0 \mathrm{~mm} \pm$ $6.4 \mathrm{SD}$, females $58.0 \mathrm{~mm} \pm 6.1 \mathrm{SD}$ ) and calculated aortic annular diameter was $20.60 \mathrm{~mm} \pm 2.2 \mathrm{SD}$ (males $21.02 \mathrm{~mm}$ $\pm 2.0 \mathrm{SD}$, females $18.47 \mathrm{~mm} \pm 1.9 \mathrm{SD}$ ). Mean circumference showed significant gender difference. Significant positive correlation was seen between the age and aortic root circumference. We describe the normal range of aortic root diameters in healthy adult autopsied Sri Lankans. The values are smaller in Sri Lankans compared to Caucasians.
\end{abstract}

Ceylon Medical Journal 2015; 60: 148-151

\section{Introduction}

The aortic root is located between the left ventricular outflow tract and the tubular portion of the aorta, and comprises three cusps, three sinuses of Valsalva and fibrous intervalvular triangles. Aortic fibrous annulus is in the form of three scallops, extending throughout the length of the aortic root, to which the aortic semilunar valve cusps are attached. The line joining the basal attachment points of the leaflet identifies the basal ring and the highest points of attachment of leaflets denotes the sinutubular junction $[1,3]$. The third ring just above basal ring represents the anatomic ventriculoarterial junction, where the ventricular myocardium changes into the aortic wall architecture (Figure 1) [1]. The echocar-diographic aortic annular measurements are taken at the basal ring [1]. Therefore the present study focused the level of basal ring.

A

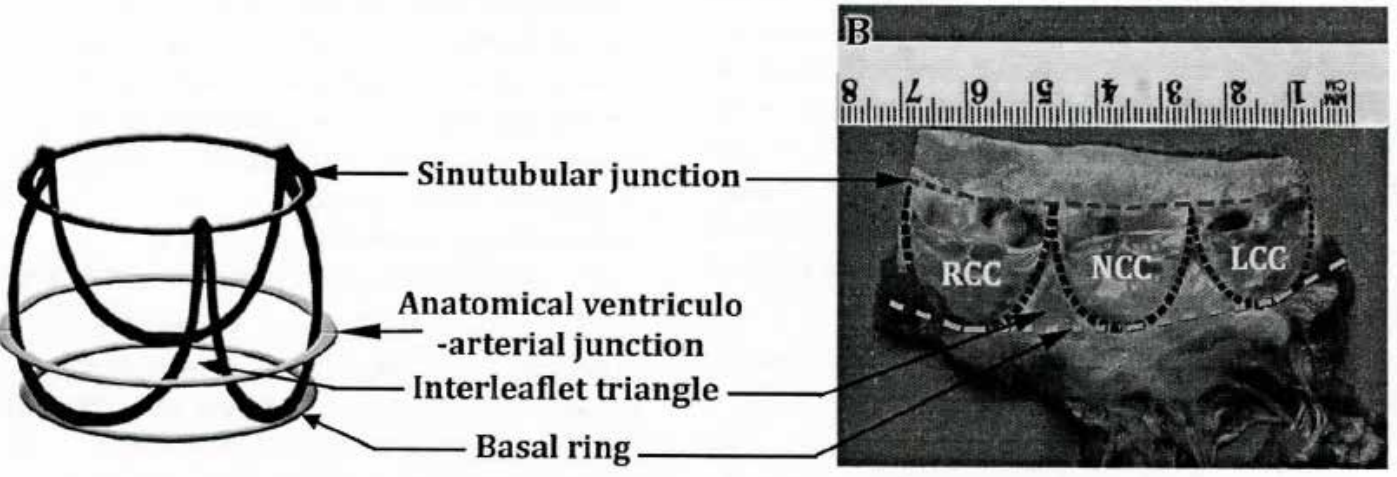

Figure 1. Aortic root showing its components

A. Schematic three dimensional diagram of the aortic root, which contains three circular rings and a scalloped ring to which the leaflets are suspended.

B. Opened aortic root at autopsy showing its components.

(RCC-right coronary cusp, LCC - left coronary cusp, NCC- non-coronary cusp)

${ }^{1}$ Department of Anatomy, Faculty of Medicine, University of Jaffna and ${ }^{2}$ Department of Anatomy, Faculty of Medical Sciences, University of Sri Jayewardenepura, Sri Lanka.

Correspondence: SU, e-mail: <sivananthini01@gmail.com>. Received 29 June and revised version accepted 25 July 2015. 
Knowledge of aortic root anatomy is a prerequisite for the interpretation of echocardiography, conservative surgical techniques, replacement with aortic valve prosthesis and new design and refinements of current valvular technology. The aortic root morphology is well documented in the literature [1-4]. Aortic root measurements in Caucasian are well documented [57]. Studies in other racial groups suggest that there is geographical variation of the norms of measurements for heart valves compared to Caucasians [8,9]. The relationship of aortic root measurements and anthropometric data is not clear. Measurements of aortic root parameters in Sri Lankans have not been documented. Therefore, the present study was undertaken to determine the aortic root diameter at its base at autopsy, and to determine the relationship between the measurements obtained at autopsy with the demographic data of the individual. These norms of measurements and their determinants are important to predict the appropriate annular size in replacement surgery and to assess the degree of valve stenosis in echocardiography.

\section{Methods}

Three hundred and twenty fresh, autopsied, adult hearts were collected from the Department of the Judicial Medical Officer, National Hospital of Sri Lanka. These hearts were from individuals who had died of causes other than heart disease and where post-mortem was carried out within 24 hours of death. Specimens were not harvested if any anomaly was detected at autopsy. Data, age and sex were obtained from the cadavers. The body weight (in kilograms) and height (in centimeters) were measured at the time of autopsy. The body surface area was determined according to the established criteria [10].

The aortic root was longitudinally opened through the commissure between the right and left coronary cusps [5]. The aortic root was then unfolded. A cotton thread was placed hugging the annulus at basal ring and the circumference was taken and the length was measured using a transparent ruler (graduated to $0.1 \mathrm{~mm}$ ) at the fresh stage (Figure 1). The diameter was calculated using the mathematical formula circumference $/ \pi[6]$.

Data analysis was done using Minitab for Windows version 14. $\mathrm{p}$ value less than 0.05 was considered significant. Independent $t$ test was used to compare means. Approval for this study was obtained from the Ethical Review Committee of the Faculty of Medicine, University of Colombo.

\section{Results}

A summary of the characteristics of cadavers is shown in Table 1. Data were analysed for 267 males and 52 females (outliers were excluded from the analysis). Age at death ranged from 18 to 78 years (mean $=43.83$ years; $\mathrm{SD}=15)$. Height for the entire group ranged from 121 to $188 \mathrm{~cm}($ mean $=163.04 \mathrm{~cm} ; \mathrm{SD}=8.7)$. Weight ranged from 38 to $97 \mathrm{~kg}($ mean $=60.23 \mathrm{~kg} ; \mathrm{SD}=9)$. The body surface area ranged from 1.21 to $2.16 \mathrm{~m}^{2}$ (mean $=1.72 \mathrm{~m}^{2} ; \mathrm{SD}=0.1$ ).

The aortic root circumference ranged from 48 to $85 \mathrm{~mm}($ mean $=64.7 \mathrm{~mm} ; \mathrm{SD}=7)$. In the males the circumference ranged from 49 to $85 \mathrm{~mm}$ (mean $=66.0$ $\mathrm{mm} ; \mathrm{SD}=6.4$ ) (Figure 3 ). In the females ranged from 48 to $69 \mathrm{~mm}($ mean $=58.0 \mathrm{~mm}, \mathrm{SD}=6.1)($ Figure 3$)$. The aortic annular diameter ranged from 15 to $27 \mathrm{~mm}$ (mean $=20.60 \mathrm{~mm} ; \mathrm{SD}=2.2$ ). In the males the mean annular diameter was $21.02 \mathrm{~mm} \pm 2.0 \mathrm{SD}$ (range $16-27 \mathrm{~mm}$ ) and in females it was $18.47 \mathrm{~mm} \pm 1.9 \mathrm{SD}$ (range15 - $22 \mathrm{~mm}$ ) (Figure 2). The mean values of aortic valve circumference at the basal ring in males and females were significantly different $(\mathrm{p}<0.001)$. Circumference of the basal ring positively correlated with age correlation coefficient $(\mathrm{r})=$ 0.604; $p<0.001)$, height $(\mathrm{r}=0.183 ; p<0.05)$ and body surface area $(\mathrm{r}=0.172 ; p<0.05)$.

\section{Fitting regression model}

A stepwise regression analysis was done to identify the variables that significantly influenced the aortic annular circumference $(p<0.05)$. We found that aortic

Table 1. Characteristics of the cadavers at autopsy

\begin{tabular}{lccc}
\hline & Male & Female & Total \\
\cline { 2 - 4 } & & Mean SD (range) & 319 \\
Number & 267 & 52 & $43.8 \pm 15(18-78)$ \\
Age (years) & $44.3 \pm 15.1(18-78)$ & $41.5 \pm 14.5(20-69)$ & $163.0 \pm 8.7(121-188)$ \\
Height (cm) & $164.8 \pm 7.6(121-188)$ & $154.1 \pm 8.8(128-180)$ & $60.2 \pm 9(38-97)$ \\
Weight (kg) & $61.2 \pm 9.1(38-97)$ & $55.3 \pm 6.6(44-69)$ & $1.72 \pm 0.1(1.2-2.2)$ \\
Body surface area $\mathrm{m}^{2}$ & $1.75 \pm 0.1(1.2-2.2)$ & $1.58 \pm 0.1(1.36-1.9)$ & \\
\hline
\end{tabular}



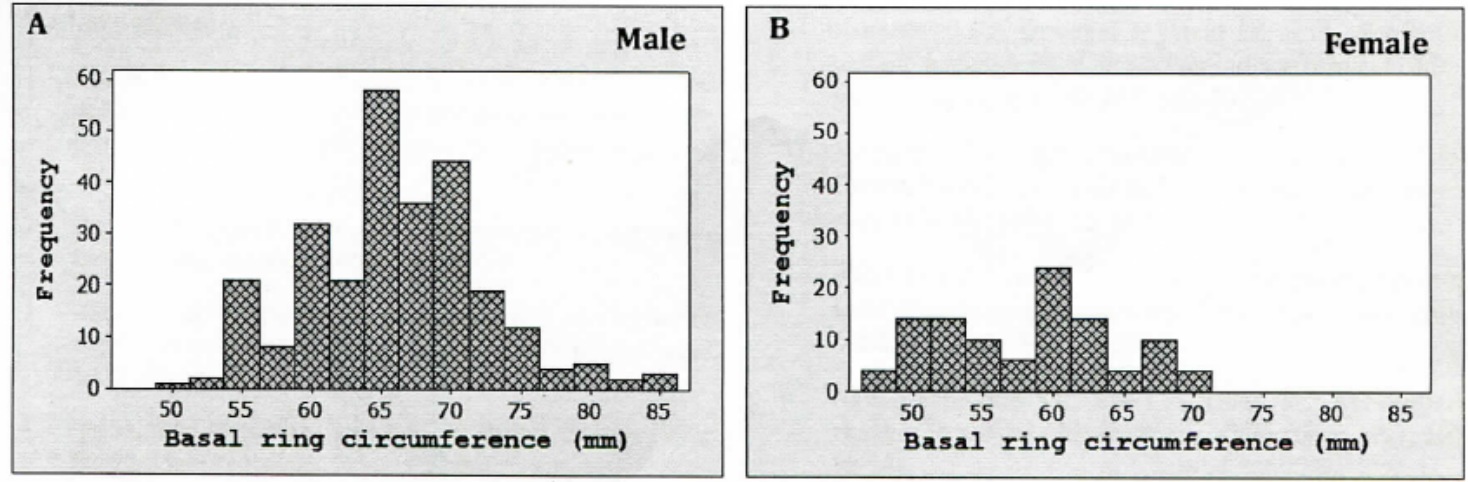

Figure 2. Distribution of aortic root circumference at the basal ring

root circumference at basal ring was $61.4+0.268$ age $7.28 \mathrm{sex}$. Sex was a dummy variable (male $=1$, female $=$ $0)$. This explained $51.2 \%$ of the overall variation $\left(\mathrm{R}^{2}=\right.$ $51.2 \%)$.

\section{Discussion}

Since this study was done on freshly autopsied adult human hearts, it excludes the error due to fixation. A previous study indicated that the limitation of valve measurements at autopsy is less important when the annulus is opened and measurements are taken [7]. The circularized aortic annulus was calculated for clinical comparison and insertion of a valve prosthesis also circularizes the annulus $[6,7]$.

A study involving Caucasians reported the mean aortic root circumference at basal ring to be $69.2 \pm 6.9 \mathrm{~mm}$ [2]. Another study reported that the mean aortic annular circumferene at basal ring in $10 \%$ formalin preserved adult Caucasians was $7.28 \mathrm{~cm} \pm 0.92$ [7]. The calculated valve diameter of this group was $23.20 \mathrm{~mm} \pm 3.3$. The mean aortic root diameter at the basal ring was reported to be $23.4 \pm 1.2 \mathrm{~mm}$ in cryo preserved specimens [6]. Comparison of our findings with the reported autopsy data at basal ring shows that the mean aortic annular circumference is smaller in Sri Lankans compared to Caucasians. Further com-parisons cannot be done due to mode of fixation.

Studies in Chinese and Indians have shown that the values for normal adults are lower than the values reported in Caucasians $[8,9]$. Aortic valve diameter in Indian hearts vary between 15 to $24 \mathrm{~mm}$ in males $(\mathrm{n}=350$, mean $19 \pm$ $2.1 \mathrm{~mm})$ and 13 to $22 \mathrm{~mm}$ in females $(\mathrm{n}=150$, mean $16.9 \pm$ $1.9 \mathrm{~mm}$ ) [8]. Our results are similar to that of Indians, but the site of measurement (whether basal ring or sinutubular junction) was not indicated in the Indian study. Among Chinese, indexed mean circumference (circumference divided by body surface area) of the hearts were notably less than that reported in Caucasians for all decades, indicating smaller heart valves in Chinese [9].

Our findings of mean aortic annular diameter being greater in males than females are supported by literature $[5,7,8]$. Accordingly men have valves that are $10 \%$ larger than women [7].

Age related dilatation of the aortic root has been consistently reported which substantiates our finding [7, $8,9]$. The aortic valve ring begins to dilate, paralleling the changes in elasticity and this dilatation is a true ageing process and most frequent cause of non-valvular forms of aortic valvular regurgitation in the elderly [5]. In contrast, a study in Chinese population concluded that there was absence of disproportional age related dilatation of aortic valve annulus in their population as seen in Caucasians [9].

Most studies have concluded that age and gender are the major determinant of aortic size. By our regression model only $51 \%$ of the variation can be explained. It shows that there is still uncertainty regarding the other measurable predictors of aortic annular circumference or diameter.

This study was carried out in fresh autopsied hearts and there may be differences in the values of live people, which in a limitation of this study.

In conclusion mean aortic annular circumference is smaller in Sri Lankans compared to Caucasians. There is a significant increase in the aortic annular circumference with age.

\section{Funding}

Partial financial support by IRQUE/QEF/Medical Study Programme, Faculty of Medicine, University of Jaffna.

\section{Acknowledgements}

We thank the staff of Department of Anatomy, University of Colombo for their valuable technical assistance. 


\section{Conflicts of interests}

There are no conflicts of interest.

\section{References}

1. Piazza N, Jaegere PD, Schultz C, et al. Anatomy of the aortic valvular complex and its implications for transcatheter implantation of the aortic valve. Circ Cardiovasc Interv $2008 ; 1: 74-81$

2. Berdajs D, Lajos P, Turina M. The anatomy of the aortic root. Cardiovasc Surg 2002; 10: 320 -7.

3. Underwood M, Khoury GEI, Deronck D, et al. The aortic root: Structure, function and surgical reconstruction. Heart 2000; 83: 376-80.

4. Reid K. The anatomy of the sinus of Valsalva. Thorax 1970; 25: 79-85.
5. Sawabe M, Hamamatsu A, Chida K, et al. Age is a major pathobiological determinant of aortic dilatation: A large autopsy study of community deaths. J Atheroscler Thromb 2011; 18: 157-65.

6. Kunzelman KS, Grande KJ, David TE, et al. Aortic root and valve relationships. Impact on surgical repair. $J$ Thorac Cardiovasc Surg 1994; 107: 162-70.

7. Westaby S, Karp RB, Blackstone EH, Bishop SP. Adult Human Valve Dimensions and Their Surgical Significance. Ame J Cardiol 1984; 53: 552-6.

8. Sahni D and Indrajit. Size of the valve and thickness of anterior walls of the ventricles of the adult Indian hearts. Indian Heart $J$ 1992; 43: 361-5.

9. Adebo OA, Lun KC, Lee CN, Chao TC. Age-Related changes in normal Chinese hearts. Chin Med J 1994; 107: 88-94.

10. McArdle WD, Katch FI, Katch VL. Exercise Physiology energy, nutrition and human performance $5^{\text {th }}$ Edition, 